\title{
DISEÑO DE INSTRUMENTO PARA LA EVALUACIÓN DE UN ENTORNO DE APRENDIZAJE COLABORATIVO
}

Pedro Andrés Certad Villarroel ${ }^{1}$ - Universidad Metropolitana, Caracas, Venezuela. pcertad@unimet.edu.ve

\section{RESUMEN}

El presente estudio propone el diseño de un instrumento para la evaluación de un Entorno de Aprendizaje Colaborativo. La necesidad surge a partir de la observación directa de una selección de ambientes de aprendizaje colaborativo y de la manifiesta inclusión de instructores expertos en contenido conceptual y con competencias en el área tecnológica pero no en aspectos relacionados con la didáctica y su discurso pedagógico. El estudio se fundamenta en la aproximación conceptual de los Entornos de Aprendizaje Colaborativo, en el Análisis de Contenido como estrategia evaluativa para un Entorno de Aprendizaje Colaborativo y en las visiones teóricas que desde la Tecnología Educativa tienen Hassan y Martín, Pere Marquès y la Universidad de Wisconsin - Eau Claire. Por su diseño es congruente con la Investigación Holística en el tipo de Investigación Proyectiva con apoyo la modalidad de Proyecto Especial el cual se elaboró en cuatro estadios: Descriptivo, Comparativo-Analítico, Explicativo y Técnico lo que cubrió desde la observación directa, pasando por la categorización, contrastación hasta el diseño del instrumento objeto del estudio. Este instrumento diseñado está basado en una Lista de Cotejo 63 ítemes los cuales cubren las categorías que emergieron de las observaciones, proporcionando un análisis de contenido a partir de la construcción de párrafos desde una lista de verbatum predefinida según la elección hecha en el instrumento, de oraciones claras y concisas que surgieron de aportes teóricos específicos, agrupado en tres párrafos, uno por cada aspecto observado (tecnológico, discursivo y didáctico).

\section{PALABRAS CLAVE}

Análisis de Contenido - Entorno de Aprendizaje Colaborativo - Investigación Holística - Discurso Pedagógico - Tecnología Educativa - Didáctica

\footnotetext{
${ }_{1}^{1}$ Pedro Andrés Certad V: Facultad de Ciencias y Arte. Departamento de Ciencias de la Educación de la Universidad Metropolitana de Caracas. Venezuela.

Correo: pcertad@unimet.edu.ve
} 


\section{DESIGN TOOL FOR EVALUATION OF A COLLABORATIVE LEARNING ENVIRONMENT}

\section{ABSTRACT}

This study proposes the design of a tool for the evaluation of a Collaborative Learning Environment. The need arises from direct observation of selected collaborative learning environments and the apparent inclusion of expert instructors in conceptual content and skills in the technological area but not in aspects of teaching and pedagogical discourse. The study is based on the conceptual approach of Collaborative Learning Environments in Content Analysis as evaluation strategy for Collaborative Learning Environment and theoretical visions from Educational Technology have Hassan and Martin, Pere Marques and the University of Wisconsin - Eau Claire. By design is consistent with Holistic Research the type of Projective Research supported mode Special Project which was developed in four stages: Descriptive, comparative-analytical, Explanatory and Technical which covered from direct observation, through the categorization, contrasting to the design of the instrument under study. This instrument designed is based on a Checklist 63 items which cover the categories that emerged from the comments, providing a content analysis from the construction of paragraphs from a list of predefined verbatum according to the choice made in the instrument of clear and concise sentences that emerged from specific theoretical contributions, grouped into three paragraphs, one for each aspect observed (technological, discursive and didactic).

\section{KEY WORDS}

Content Analysis - Collaborative Learning Environment - Holistic Research - Speech Teaching - Educational Technology - Teaching.

\section{INTRODUCCIÓN}

La inclusión de la Tecnología de la Información y la Comunicación con la Web 2.0 en la educación representa un desafío y una innovación en los procesos de enseñanza para un aprendizaje colaborativo. Su aplicación se enmarca en la Tecnología Educativa, en el uso de Entornos de Aprendizaje Colaborativo (EAC) para la facilitación de situaciones didácticas fundamentadas en contenidos conceptuales, procedimentales y actitudinales.

Los docentes como instrumentos facilitadores del aprendizaje, valiéndose de las bondades otorgadas por los EAC, desarrollan sus cursos con una mayor comodidad gracias a la cantidad de herramientas disponibles en la Web para la demostración de los contenidos. Las asignaturas pueden integrarse en un EAC con el simple uso de un tutorial, adecuando las plataformas a la didáctica. El uso de un instrumento de análisis de contenido puede guiar y refinar la construcción de los entornos de aprendizaje otorgando lineamientos claros que proporcionen al constructor de éste un camino adecuado para que el ambiente cumpla con el fin para el cual fue diseñado: instruir. 


\subsection{Descripción del tema de estudio}

En la Sociedad del Conocimiento el hecho educativo ha ido cambiando en cada una de sus modalidades: educación regular, educación virtual y educación a distancia (Castañeda y Sánchez, 2009) por el impacto que ha introducido la aplicación de la Tecnología de la Información y la Comunicación (TIC).

Para el Dr. Julio Cabero de la Universidad de Sevilla, la influencia de las TIC en los procesos de enseñanza y de aprendizaje viene dada, entre otros factores, por la creación de entornos más flexibles para el aprendizaje, potenciación de entornos interactivos y el favorecimiento del aprendizaje colaborativo rompiendo así los clásicos escenarios formativos, (Fernández y Martínez, 2009) lo que transitivamente se convierte en la recomendación de uso de los Entornos Aprendizaje Colaborativo (EAC).

Un EAC, de manera resumida, es entendido como un lugar donde los alumnos deben trabajar juntos, ayudándose unos a otros, usando una variedad de instrumentos y recursos informativos que permitan la búsqueda de los objetivos de aprendizaje y actividades para la solución de problemas (Wilson, 1995; Ferraté, 1997). Este entorno se vale de herramientas telemáticas hospedadas en la Web 2.0 para promover un aprendizaje colaborativo, interactivo, significativo $\mathrm{y}$, de alguna forma, una gestión del conocimiento (Salinas, 2004).

Gracias a la disponibilidad de dichas herramientas interactivas y, a las bondades que proporciona el uso de Internet en cuanto a la existencia de información actualizada para estos modernos ambientes de aprendizaje, se hace posible que un instructor, no experto en construcción de entornos de aprendizaje pero si en contenido conceptual, diseñe, construya y ponga en funcionamiento un EAC a través del uso de tutoriales básicos a partir de plantillas prediseñadas (Tondeur, et.al., 2007). Pero en esta ejecución mecánica tutorizada, es igualmente posible que se descuiden aspectos importantes para la construcción del entorno como lo son: la corriente psicológica que debe ser aplicada para la explicación del contenido, las estrategias didácticas presentadas, la construcción idónea del discurso pedagógico verbal y no verbal, la confiabilidad de la fuente de información y la disposición del contenido dentro del entorno de aprendizaje. (Yusef et.al., 2006)

Esa construcción empírica del EAC requiere de un estudio exhaustivo que permita determinar la forma idónea de su elaboración con el fin único que persigue: promover el aprendizaje a través de la diagramación adecuada del entorno, del discurso pedagógico pertinente y de la aplicación de estrategias de enseñanza. (Adúriz, 2010)

Por lo anteriormente descrito, en el Trabajo Especial de Grado realizado se pretendió: Diseñar un instrumento para el análisis de contenido de un Entorno de Aprendizaje Colaborativo, y surgen las siguientes interrogantes: ¿Qué elementos constituyen un EAC en cuanto a su contenido general?, ¿Qué categorías proponen los teóricos que deben estar presentes en un EAC?, ¿Qué categorías deben conformar un instrumento para el análisis de contenido de un EAC?, lo que conduce a la pregunta principal de investigación: ¿Será posible diseñar un instrumento que permita el análisis de contenido de un EAC? 


\section{OBJETIVO:}

Diseñar un instrumento para el análisis de contenido de un Entorno de Aprendizaje Colaborativo.

\section{METODOLOGÍA}

Una vez recabada la información teórica y referencial que sustenta la construcción del instrumento para el Análisis de Contenido de un EAC, se requiere la ejecución metodológica, para ello este capítulo presenta: a) la metodología empleada para el diseño del instrumento, b) el diseño procedimental, c) el diseño instrumental y d) el contexto de aplicación.

\subsection{Diseño metodológico}

Tomando en cuenta el objetivo general de este estudio es posible enmarcarlo en el Paradigma Holístico de investigación. Para Hurtado (2000) la Investigación Holística "...integra diversos modelos epistémicos y se concibe como un proceso global, evolutivo, integrador, concatenado y sinérgico, con aspectos secuenciales y simultáneos". Así mismo:

Trabaja los procesos que tienen que ver con la invención, con la formulación de propuestas novedosas, con la descripción y la clasificación, considera la creación de teorías y modelos, la indagación acerca del futuro, la aplicación de soluciones, y la evaluación de proyectos, programas y acciones sociales, entre otras cosas (Hurtado, Ob.cit.).

Dentro de esta Investigación Holística y teniendo en cuenta, de nuevo, el objetivo general de este diseño es posible decir que el estudio está en el nivel comprensivo, al proponer el Diseño de un instrumento para el análisis de contenido de un Entorno de Aprendizaje Colaborativo.

De acuerdo a lo anteriormente descrito, según la clasificación de este Paradigma Holístico y, en la relación nivel con tipo de objetivo, está ubicado en el tipo de Investigación Proyectiva, la cual según Hurtado (2000): "son todas aquellas investigaciones que conducen a inventos, programas, diseños o a creaciones dirigidas a cubrir una determinada necesidad, y basadas en conocimientos anteriores" (p.323)

Así mismo, esta Investigación Proyectiva tiene la modalidad de Proyecto Especial. Esta modalidad es entendida según la Universidad Pedagógica Experimental Libertador (2006) como: “...trabajos que lleven a creaciones tangibles, susceptibles de ser utilizadas como soluciones a problemas demostrados.." continúa especificando que: “...Se incluyen en esta categoría los trabajos de elaboración de libros de texto y de materiales de apoyo educativo, el desarrollo de software, prototipos y de productos tecnológicos en general...." (p.14) siendo congruentes tanto con la esencia del proyecto como con las líneas de investigación de la especialización a la cual se opta, la propuesta es entonces, tecnológica e incluyente de categorías didácticas y discursivas que permitan el reconocimiento del contenido presente en un EAC y su posterior análisis.

Esta modalidad de Proyecto Especial conlleva a un proceso continuo y progresivo que obliga a haber transcurrido otros estadios-fases precedentes:

a. Estadio Descriptivo. 
b. Estadio Comparativo y Analítico.

c. Estadio Explicativo.

d. Estadio Técnico y de Diseño

\subsection{Diseño procedimental}

Para cumplir con el objetivo general planteado en este diseño se hace necesario parcelar el desarrollo de la Investigación Proyectiva en cuatro estadios (Hurtado, 2000), a saber:

a. Estadio Descriptivo: el cual comprendió el diagnóstico de la realidad a intentar modificar, revisión documental que proporcionó el estado del arte, los fundamentos teóricos de donde surgen las categorías propuestas a contener un EAC y, la descripción de una selección de EAC.

b. Estadio Comparativo y Analítico: que comprendió el trabajo en sí con la información recogida por el Estadio Descriptivo. Se aplicó el método de la Triangulación. Para Pérez Serrano (1998; c.p. Ramírez; 2007) este método consiste en "recoger información o hacer observaciones desde una variedad de ángulos o perspectivas para después compararlas o contrastarlas". La Triangulación se aplicó por la contrastación de las categorías propuestas para la construcción de un entorno de aprendizaje colaborativo según los aportes teóricos recogidos en el capítulo dos y en el Estadio Descriptivo con las categorías emergentes, entendiendo éstas como el resultado de un proceso de clasificación de datos en torno a ideas, temas y conceptos que irán emergiendo de la lectura del propio material (Porta y Silva; 2003), halladas en los EAC por la observación directa. Las fuentes de la información que posibilitaron la Triangulación fueron: documentales y observacionales. Una vez tomadas las categorías sugeridas por la información teórica y las categorías emergentes obtenidas por la observación de los EAC seleccionados se obtuvieron aquellas categorías comunes en ambos casos.

c. Estadio Explicativo: con la selección de las categorías comunes en la Triangulación y su complementación con el apoyo teórico, lo que respalda la categoría de donde surgió la formulación de los ítemes que integraron el Instrumento para el Análisis de Contenido.

Las categorías que emergieron se agruparon en dimensiones de tipo: Didáctico, Discursivo y Tecnológico, tomando en cuenta tres criterios: a) la característica de la categoría emergente, b) el origen epistémico y, c) el contexto académico del EAC.

d. Estadio Técnico y de Diseño: en el cual, ya obtenidas las categorías y agrupadas en dimensiones de estudio se elaboró la Tabla de Operacionalización de Variables a partir del propósito del instrumento y según las dimensiones halladas, la Tabla de Ítemes los cuales surgieron de los aportes teóricos de cada categoría en modo de aseveración y la Tabla de Verbatum los cuales se apoyan en el aporte teórico respectivo tomando en cuenta las consecuencias de las presencia o ausencia de la categoría. Todo esto se muestra en el Capítulo siguiente. 
En cuanto al diseño se construyeron dos instrumentos: a) instrumento tradicional $y, b$ ) instrumento digital. No existen variaciones entre ellos en cuanto a los ítemes pero, mientras en el instrumento tradicional los verbatum deben ser agrupados y escritos por quien aplica el instrumento, en el instrumento digital gracias a la programación HTML y PHP la selección booleana de los ítemes arroja tres párrafos de verbatum agrupados por las dimensiones predefinidas.

\subsection{Diseño instrumental}

El ser humano está en constante interacción con su ambiente lo que le permite un encuentro continuo con múltiples tipos y cantidades de información. En aspectos formales de la vida como el ámbito académico por ejemplo, esta información debe ser trabajada en base a procesos cognitivos superiores que permitirán sacar un mayor provecho a su contenido. Para ello es recomendable la aplicación de herramientas que guíen esta captación de datos y metadatos como lo son los instrumentos de recolección de información.

Para Arias (2006), los instrumentos de recolección de datos "son los medios materiales que se emplean para recoger y almacenar la información" (p. 69). En esta propuesta en particular, hay dos grupos de instrumentos: a) el instrumento de recolección de información conocido como Cuadro de Registro y Clasificación de las Categorías que se aplicó tanto en el Estadio Comparativo-Analítico en el Capítulo II como en el Estadio Explicativo del Capítulo IV y, b) el instrumento diseñado, el cual, fue construido más no le fue aplicado a población alguna, sino que es el producto tecnológico objeto de estudio (diferente al objeto de análisis). Tampoco fue concebido en ningún momento como una herramienta instrumental que medió una obtención de información para un análisis a posteriori, en pocas palabras, escapó a esta investigación la aplicación del instrumento diseñado, lo que más adelante se explica con detalle.

\subsection{El Instrumento en Formato Tradicional}

La idea en la escogencia de un tipo de instrumento base para amoldarlo al instrumento de análisis de contenido se centró en poder observar la existencia o ausencia de categorías específicas y comunes en Entornos de Aprendizaje Colaborativo. Es por ello que el tipo de instrumento que más se adaptó a los requerimientos ideales fue la Lista de Cotejo.

La Lista de Cotejo, también conocida como Lista de Control o de Verificación es un instrumento que indica, efectivamente y tal como se requiere en este diseño, la presencia o ausencia de aspectos, categorías o conductas a ser observadas. (Arias, 2006)

La Lista de Cotejo en formato tradicional tiene tres columnas, a saber: la primera columna ubicada a la izquierda, contiene la categoría a observar en el EAC, la columna central dispone de un casilla para marcar en caso de que la categoría esté presente con un "SI" y una tercera columna a la derecha contiene una casilla para marcar en caso que la categoría esté ausente con un "NO". 


\subsection{El análisis de contenido como técnica para la evaluación de un EAC.}

Para abordar el manejo de la información en un contexto ahora evaluativo, se debe seleccionar la técnica con la cual el investigador/observador espere obtener mayor calidad en el procesamiento dichas informaciones. Para este estudio y tal como se mencionó previamente en las categorizaciones de los EAC observados, se aplica el Análisis de Contenido a través de un instrumento construido para tal fin y cuyo resultado del análisis surge de la reunión de grupos de verbatums elaborados, y éstos a su vez, a partir de las observaciones que haga el evaluador sobre el entorno de aprendizaje. Para Piñuel (2002):

Se suele llamar análisis de contenido al conjunto de procedimientos interpretativosde productos comunicativos (mensajes, textos o discursos) que proceden de procesos singulares de comunicación previamente registrados, y que, basados en técnicas de medida, a veces cuantitativas (estadísticas basadas en el recuento de unidades), a veces cualitativas (lógicas basadas en la combinación de categorías) tienen por objeto elaborar y procesar datos relevantes sobre las condiciones mismas en que se han producido aquellos textos, o sobre las condiciones que puedan darse para su empleo posterior. (p.3)

Igualmente Hostil (1969) aboga por una definición que aporta varios aspectos muy importantes respecto a la realizada por Piñuel: "El análisis de contenido es una técnica de investigación para formular inferencias identificando de manera sistemática y objetiva ciertas características específicas". A partir de lo anteriormente descrito por los autores, es posible encontrar una triple vertiente para la aplicación de la técnica, específicamente en un EAC: el análisis de mensajes, de textos y de discursos.

El análisis de contenido está compuesto por cuatro aspectos fundamentales: a) el objeto de análisis, b) las reglas de codificación, c) el sistema de categorías y d) las inferencias.

a. El objeto de análisis: básicamente este aspecto conviene a lo que es ¿qué se va a analizar?. En una investigación documental, o de campo por ejemplo este objeto se convierte en el tema de análisis. Como en este caso, el instrumento construido realiza el análisis de contenido, el objeto de estudio son los Entornos de Aprendizaje Colaborativo.

b. Las reglas de la codificación: Tratar el material es codificarlo. La codificación consiste en una transformación mediante reglas precisas de los datos brutos del texto. Esta transformación o descomposición del texto permite su representación en índices numéricos o alfabéticos. (Abela, 2003). En este sentido se tomará como regla la Frecuencia en la cual se registra la repetición de una característica que pudiese convertirse en una categoría.

c. El sistema de categorías: A este respecto, Bardin (1996), lo concibe como "...una operación de clasificación de elementos constitutivos de un conjunto por diferenciación, tras la agrupación por analogía, a partir de criterios previamente definidos". Clasificar elementos en categorías impone buscar lo que cada uno de ellos tienen en común con los otros (Abela, ob.cit). Este sistema agrupó las categorías que fueron emergiendo tanto en la búsqueda documental de las 
propuestas de los teóricos como en la observación directa de los EAC que fueron sometidos a un análisis.

d. Inferencias: este último aspecto es meramente deductivo. Consiste en buscar algunas conclusiones "contenidas" de manera explícita o implícita en el propio texto (Abela, ob.cit). Este proceso permitió cerrar las categorizaciones que facilitaron las construcción de las tablas operacionales, las tablas de ítemes y las tablas de verbatums las cuales se muestran más adelante.

Dentro del Análisis de Contenido que se le realizaron a los EAC a través del Instrumento propuesto, se precisa el Análisis de Contenido Temático pues considera la presencia de términos o conceptos, con independencia de las relaciones surgidas entre ellos. (Abela, ob cit.) Quizás la técnica más frecuente consiste en buscar -y eventualmente analizar más detenidamente, con otra técnica- unidades en donde aparece una determinada temática lo que reafirma la regla de codificación adoptada para la categorización a posteriori.

Así mismo, se acompañó el Análisis de Contenido Temático con el Análisis de Contenido Cualitativo de tipo inductivo, el cual consiste en un conjunto de técnicas sistemáticas interpretativas del sentido oculto de los textos con procedimientos reductivos por lo que es incluyente de aspectos discursivos verbales e iconográficos, siendo esto pertinente para este estudio. (Abela, ob.cit)

\section{DISCUSIÓN}

Una vez descrito el procedimiento metodológico a seguir para el manejo de la información proveniente de las revisiones teóricas y observaciones directas de los EAC escogidos, se procedió a la construcción del Instrumento que se describe en este cuarto capítulo que contiene: el Sistema de Categorización, el Sistema de Operacionalización de Variables, la Tabla de Ítemes y la Tabla de Verbatums y por último, los modelos de Instrumento diseñados tanto en formato tradicional como en formato digital.

\subsection{Sistema de categorización}

Tal como se mencionó anteriormente, este sistema agrupó las categorías que fueron emergiendo tanto en la búsqueda documental de las propuestas de los teóricos como en la observación directa de los EAC que fueron sometidos a un análisis.

a. Categorías comunes entre las propuestas teóricas sobre los EAC y los EAC observados.

Los datos e informaciones que componen la siguiente tabla surgen de las categorías que emergieron en las observaciones teóricas y directas.

\section{Tabla 1.}


Categorías comunes entre las propuestas teóricas y la observación directa sobre los EAC.

\begin{tabular}{|c|c|c|c|c|c|c|c|}
\hline \multirow[t]{2}{*}{$\begin{array}{l}\text { Pere } \\
\text { Marq } \\
\text { uès }\end{array}$} & $\begin{array}{l}\text { UWE } \\
\text { C }\end{array}$ & $\begin{array}{c}\text { Hassa } \\
\text { n } \\
\text { Martin }\end{array}$ & $\begin{array}{c}\text { Entorn } \\
\text { o } 1\end{array}$ & $\begin{array}{c}\text { Entorn } \\
\text { o } 2\end{array}$ & $\begin{array}{c}\text { Entorn } \\
\text { o } 3\end{array}$ & Categorías & $\begin{array}{c}\text { Cobertura } \\
\%\end{array}$ \\
\hline & $X$ & $X$ & $X$ & $X$ & $X$ & $\begin{array}{l}\text { Dirección en } \\
\text { la web }\end{array}$ & 83,3 \\
\hline \multirow[t]{2}{*}{$X$} & $x$ & $X$ & $x$ & $X$ & $x$ & $\begin{array}{l}\text { Velocidad de } \\
\text { carga }\end{array}$ & 100 \\
\hline & $x$ & $X$ & $x$ & $x$ & $x$ & $\begin{array}{l}\text { Contenido } \\
\text { autoexplicati } \\
\text { vo }\end{array}$ & 83,3 \\
\hline$X$ & & $X$ & & $X$ & & $\begin{array}{l}\text { Mapa de } \\
\text { navegación }\end{array}$ & 50 \\
\hline \multirow[t]{3}{*}{$X$} & & $X$ & & $X$ & $x$ & $\begin{array}{l}\text { Menú de } \\
\text { ayuda }\end{array}$ & 83,3 \\
\hline & $X$ & & & & & Censura & 16,6 \\
\hline & & $x$ & & & $X$ & $\begin{array}{l}\text { Compatibilid } \\
\text { ad }\end{array}$ & 33,3 \\
\hline$X$ & $X$ & $X$ & $X$ & $X$ & $X$ & $\begin{array}{l}\text { Ejecución de } \\
\text { programas y } \\
\text { herramientas }\end{array}$ & 100 \\
\hline$X$ & & & & & & $\begin{array}{l}\text { Tecnología } \\
\text { avanzada }\end{array}$ & 16,6 \\
\hline$X$ & & & & $X$ & & $\begin{array}{l}\text { Servicios } \\
\text { informativos }\end{array}$ & 33,3 \\
\hline$X$ & $X$ & $X$ & $X$ & $X$ & $X$ & $\begin{array}{l}\text { Bidireccionali } \\
\text { dad }\end{array}$ & 100 \\
\hline$X$ & & & $X$ & $X$ & $X$ & $\begin{array}{l}\text { Canales de } \\
\text { comunicación }\end{array}$ & 66,6 \\
\hline$X$ & & & $X$ & $X$ & $X$ & $\begin{array}{l}\text { Actividades } \\
\text { interactivas }\end{array}$ & 66,6 \\
\hline$X$ & & & $x$ & $x$ & $x$ & $\begin{array}{l}\text { Incrustacione } \\
\text { s de } \\
\text { herramientas } \\
\text { de autor }\end{array}$ & 66,6 \\
\hline$X$ & & $X$ & $x$ & $X$ & $x$ & $\begin{array}{l}\text { Herramientas } \\
\text { multimediale } \\
\text { s }\end{array}$ & 86,6 \\
\hline
\end{tabular}




\begin{tabular}{|c|c|c|c|c|c|c|c|}
\hline$X$ & & & & & & $\begin{array}{l}\text { Herramientas } \\
\text { lúdicas }\end{array}$ & 16,6 \\
\hline$X$ & $x$ & $X$ & $X$ & $X$ & $X$ & $\begin{array}{l}\text { Hipervínculo } \\
\text { s }\end{array}$ & 100 \\
\hline \multirow[t]{6}{*}{$x$} & $X$ & $X$ & $X$ & $X$ & $X$ & $\begin{array}{l}\text { Información } \\
\text { actualizada }\end{array}$ & 100 \\
\hline & $X$ & & & & & $\begin{array}{l}\text { Extensión de } \\
\text { la } \\
\text { información }\end{array}$ & 16,6 \\
\hline & & & $X$ & $X$ & & Licencia & 33,3 \\
\hline & & & $x$ & $x$ & & $\begin{array}{l}\text { Suscripción o } \\
\text { Invitación }\end{array}$ & 33,3 \\
\hline & & $x$ & & $x$ & & $\begin{array}{l}\text { Organización } \\
\text { de la } \\
\text { información }\end{array}$ & 33,3 \\
\hline & $X$ & & & & & $\begin{array}{l}\text { Datos } \\
\text { estadísticos }\end{array}$ & 16,6 \\
\hline$X$ & $X$ & & & & & $\begin{array}{l}\text { Buscadores } \\
\text { Web }\end{array}$ & 33,3 \\
\hline$X$ & & & & & & Repositorios & 16,6 \\
\hline$x$ & $X$ & $X$ & $X$ & $X$ & $X$ & $\begin{array}{l}\text { Diseño de } \\
\text { pantallas }\end{array}$ & 100 \\
\hline \multirow[t]{2}{*}{$X$} & $X$ & $X$ & $X$ & $X$ & $X$ & $\begin{array}{l}\text { Calidad } \\
\text { técnica y } \\
\text { estética en } \\
\text { sus } \\
\text { elementos }\end{array}$ & 100 \\
\hline & & $x$ & $x$ & $x$ & $X$ & $\begin{array}{l}\text { Medidas de } \\
\text { los cuadros }\end{array}$ & 66,6 \\
\hline \multirow[t]{2}{*}{$X$} & $x$ & $X$ & $X$ & $X$ & $X$ & $\begin{array}{l}\text { Entorno } \\
\text { interesante }\end{array}$ & 100 \\
\hline & & $X$ & $X$ & $X$ & $X$ & $\begin{array}{l}\text { Disposición } \\
\text { de las } \\
\text { imágenes }\end{array}$ & 66,6 \\
\hline \multirow[t]{2}{*}{$x$} & $X$ & & & $X$ & $X$ & $\begin{array}{l}\text { Espacios } \\
\text { publicitarios }\end{array}$ & 66,6 \\
\hline & & $x$ & $x$ & $x$ & $X$ & $\begin{array}{l}\text { Imagen del } \\
\text { autor del } \\
\text { entorno }\end{array}$ & 66,6 \\
\hline
\end{tabular}




\begin{tabular}{|c|c|c|c|c|c|c|c|}
\hline & & $x$ & $x$ & $X$ & $x$ & Tipografía & 66,6 \\
\hline \multirow[t]{16}{*}{$X$} & $x$ & $X$ & $x$ & $X$ & $X$ & $\begin{array}{l}\text { Descripción } \\
\text { del Autor del } \\
\text { entorno }\end{array}$ & 100 \\
\hline & $X$ & & $X$ & & & $\begin{array}{l}\text { Derechos de } \\
\text { Autor }\end{array}$ & 33,3 \\
\hline & & & $X$ & $X$ & $X$ & Ortografía & 50 \\
\hline & & & $X$ & $X$ & $X$ & $\begin{array}{l}\text { Signos de } \\
\text { puntuación }\end{array}$ & 50 \\
\hline & $X$ & $X$ & $X$ & $X$ & $X$ & $\begin{array}{l}\text { Legibilidad } \\
\text { del texto } \\
\text { escrito }\end{array}$ & 66,6 \\
\hline & & $X$ & $X$ & & & Referencias & 33,3 \\
\hline & & $X$ & $X$ & $X$ & $X$ & & 66,6 \\
\hline & & & & & & Coherencia & \\
\hline & & $X$ & $x$ & $X$ & $x$ & & 66,6 \\
\hline & & & & & & Cohesión & \\
\hline & & $X$ & $x$ & $X$ & $X$ & $\begin{array}{l}\text { Códigos } \\
\text { comunicativo } \\
\text { s }\end{array}$ & 66,6 \\
\hline & $x$ & & & & & $\begin{array}{l}\text { Descripción } \\
\text { del contexto }\end{array}$ & 16,6 \\
\hline & $x$ & & & & & $\begin{array}{l}\text { Información } \\
\text { histórica }\end{array}$ & 16,6 \\
\hline & & & $X$ & $x$ & $X$ & $\begin{array}{l}\text { Confianza en } \\
\text { el discurso } \\
\text { escrito }\end{array}$ & 50 \\
\hline & & & $X$ & $X$ & $X$ & $\begin{array}{l}\text { Categoría del } \\
\text { discurso } \\
\text { escrito }\end{array}$ & 50 \\
\hline & & & $X$ & $X$ & $X$ & $\begin{array}{l}\text { Planos del } \\
\text { discurso } \\
\text { escrito }\end{array}$ & 50 \\
\hline$X$ & & $X$ & $X$ & $X$ & $X$ & $\begin{array}{l}\text { Objetivos y } \\
\text { propósito del } \\
\text { DI }\end{array}$ & 83,3 \\
\hline$X$ & & $X$ & $X$ & $X$ & $X$ & $\begin{array}{l}\text { Contenidos } \\
\text { del DI }\end{array}$ & 83,3 \\
\hline
\end{tabular}




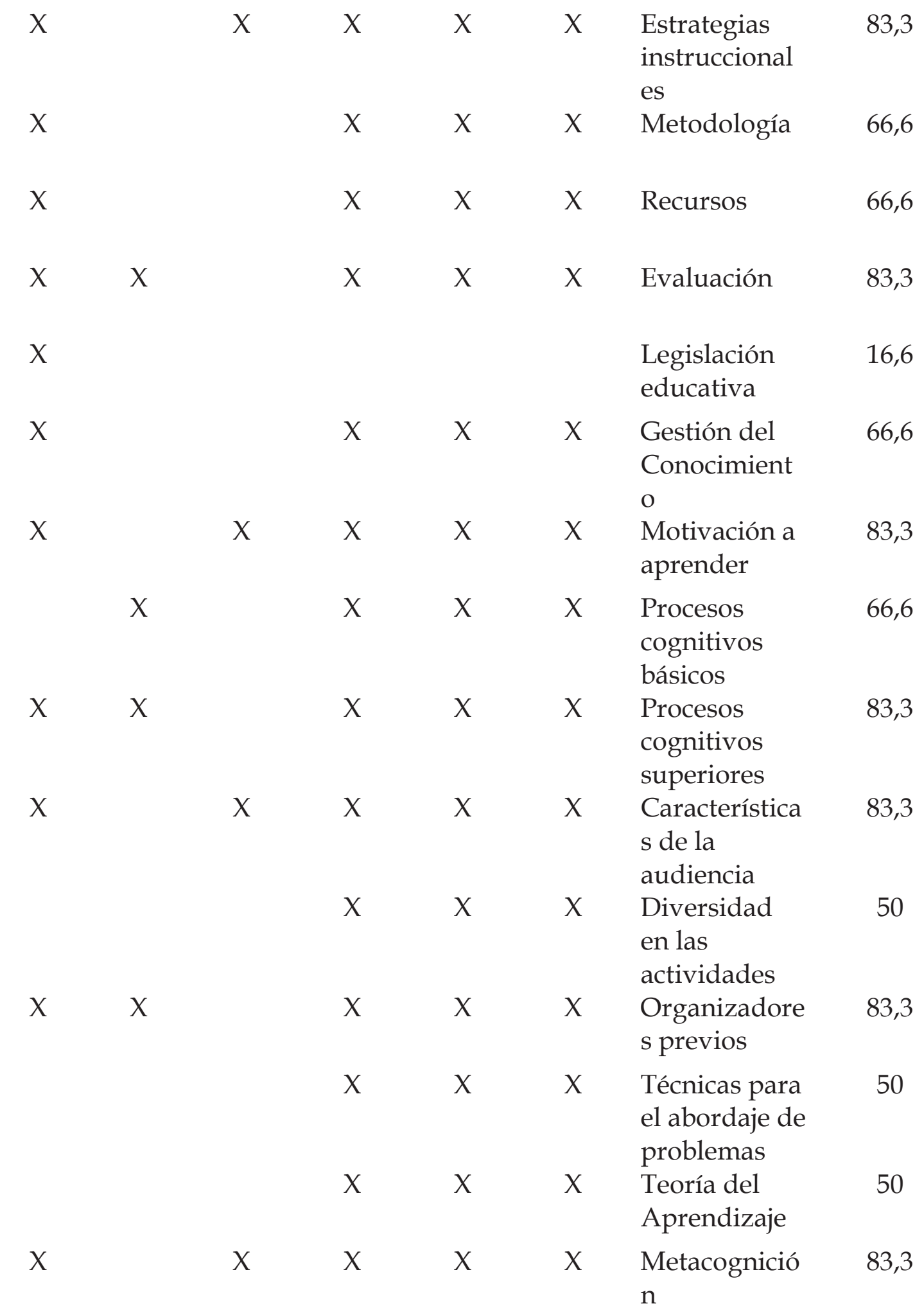

Fuente: Elaboración Propia

A partir de la información recabada y mostrada en el tabla anterior (ver tabla 7) es posible seleccionar el siguiente grupo de categorías (ver tabla 8) a ser presentadas en el Sistema de Operacionalización de Variables (ver tabla 9). Para la escogencia se tomaron en cuentas dos consideraciones: 
a) Que la categoría alcance un porcentaje mayor o igual al $60 \%$ entre las observaciones teóricas y las observaciones directas a EAC. Con este criterio la cobertura sería por mayoría de repeticiones.

b) Que la categoría alcanzara una cobertura absoluta (100\%) llamada saturación categórica en alguna de las observaciones (teóricas o directas) lo que se traduce en un $50 \%$ de la cobertura total.

Según estas consideraciones, las categorías seleccionadas fueron:

\section{Tabla 2.}

Categorías seleccionadas para el Instrumento para el Análisis de Contenido de un EAC.

\section{ASPECTOS OBSERVADOS}

Tecnológicos

Discursivos

\section{CATEGORIA}

Dirección en la web

Velocidad de carga

Contenido

autoexplicativo

Mapa de navegación

Menú de ayuda

Ejecución de programas

y herramientas

Bidireccionalidad

Canales de comunicación

Actividades interactivas

Incrustaciones de

herramientas de autor

Herramientas

multimediales

Hipervínculos

Información actualizada

Diseño de pantallas

Calidad técnica y estética

en sus elementos

Medidas de los cuadros

Entorno interesante

Disposición de las

imágenes

Espacios publicitarios

Imagen del autor del

entorno

Tipografía

Descripción del Autor

del entorno 


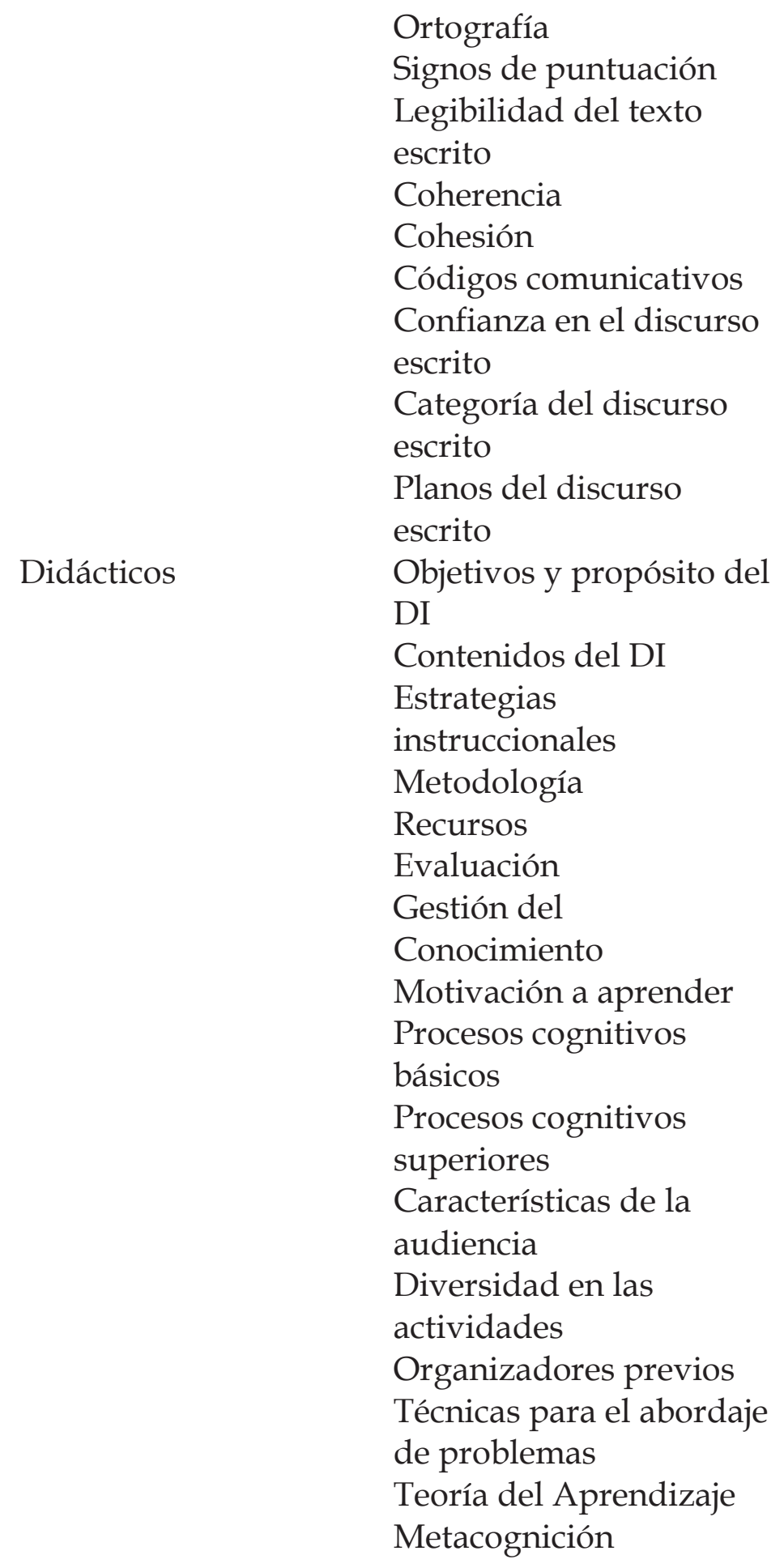

Fuente: Elaboración Propia

\subsection{Sistema de operacionalización de variables}

Instrumento: Instrumento de Análisis de Contenido - Lista de Cotejo.

Propósito del Instrumento: Analizar el contenido presente en un Entorno de Aprendizaje Colaborativo. 
Tabla 3.

Sistema de Operacionalización de Variables

\begin{tabular}{|c|c|c|c|c|c|}
\hline Dimensión & $\begin{array}{c}\text { Sub- } \\
\text { dimensió } \\
\mathbf{n}\end{array}$ & Significado & Categoría & $\begin{array}{c}\text { Tipo } \\
\text { de ítem }\end{array}$ & $\begin{array}{l}\text { Número } \\
\text { del Ítem }\end{array}$ \\
\hline \multirow[t]{13}{*}{$\begin{array}{l}\text { Contenido } \\
\text { Tecnológic } \\
\text { o-Digital }\end{array}$} & $\begin{array}{l}\text { Facilidad } \\
\text { de Uso }\end{array}$ & $\begin{array}{l}\text { Permite conocer la } \\
\text { facilidad de uso y } \\
\text { acceso que tiene el EVA }\end{array}$ & $\begin{array}{l}\text { Dirección en la } \\
\text { web }\end{array}$ & $\begin{array}{c}\text { Dicotó } \\
\text { mico }\end{array}$ & 1 \\
\hline & & & $\begin{array}{l}\text { Velocidad de } \\
\text { carga }\end{array}$ & & 2 \\
\hline & & & $\begin{array}{l}\text { Contenido } \\
\text { autoexplicativo }\end{array}$ & & 3 \\
\hline & & & $\begin{array}{l}\text { Mapa de } \\
\text { navegación }\end{array}$ & & 4 \\
\hline & & & Menú de ayuda & & 5 \\
\hline & $\begin{array}{l}\text { Interactivi } \\
\text { dad }\end{array}$ & $\begin{array}{l}\text { Permite conocer la } \\
\text { posibilidad de } \\
\text { interacción entre el } \\
\text { usuario y el EVA }\end{array}$ & $\begin{array}{l}\text { Ejecución de } \\
\text { programas y } \\
\text { herramientas }\end{array}$ & $\begin{array}{c}\text { Dicotó } \\
\text { mico }\end{array}$ & 6 \\
\hline & & & $\begin{array}{l}\text { Bidireccionalida } \\
\text { d }\end{array}$ & & 7 \\
\hline & & & $\begin{array}{l}\text { Canales de } \\
\text { comunicación }\end{array}$ & & $8,9,10$ \\
\hline & & & $\begin{array}{l}\text { Actividades } \\
\text { interactivas }\end{array}$ & & 11,12 \\
\hline & & & $\begin{array}{l}\text { Incrustaciones } \\
\text { de herramientas } \\
\text { de autor }\end{array}$ & & 13 \\
\hline & Recursos & $\begin{array}{l}\text { Permite conocer los } \\
\text { tipos de recursos para } \\
\text { la instrucción } \\
\text { utilizados en el EVA }\end{array}$ & $\begin{array}{l}\text { Herramientas } \\
\text { multimediales }\end{array}$ & $\begin{array}{c}\text { Dicotó } \\
\text { mico }\end{array}$ & 14,15 \\
\hline & & & Hipervínculos & & 16 \\
\hline & & & $\begin{array}{l}\text { Información } \\
\text { actualizada }\end{array}$ & & 17,18 \\
\hline $\begin{array}{l}\text { Contenido } \\
\text { Discursivo }\end{array}$ & $\begin{array}{l}\text { Discurso } \\
\text { Iconográfi } \\
\text { co } \\
\text { (no } \\
\text { verbal) }\end{array}$ & $\begin{array}{l}\text { Permite conocer el } \\
\text { discurso no verbal } \\
\text { empleado en la } \\
\text { construcción del EVA }\end{array}$ & $\begin{array}{l}\text { Diseño de } \\
\text { pantallas }\end{array}$ & $\begin{array}{c}\text { Dicotó } \\
\text { mico }\end{array}$ & 19 \\
\hline
\end{tabular}


Calidad técnica

y estética en sus

elementos

Medidas de los

cuadros

Entorno

interesante

Disposición de

las imágenes

Espacios

publicitarios

Imagen del

autor del

entorno

Tipografía

$\begin{array}{ll}\text { Discurso } & \text { Permite conocer el } \\ \text { Verbal } & \text { discurso verbal } \\ & \text { empleado en la } \\ & \text { construcción del EVA }\end{array}$

Descripción del

Autor del

entorno

Ortografía

Signos de

puntuación

Legibilidad del

texto escrito

Coherencia

Cohesión

Códigos

comunicativos

Confianza en el

discurso escrito

Categoría del

discurso escrito

Planos del

discurso escrito

Contenido Diseño Permite reconocer los

Objetivos y

propósito del

DI nal

componentes del

Diseño Instruccional
$20,21,22$

23

24

$25,26,27$

28

29

$30,31,32$

Dicotó

mico

Dicotó

45

mico

(DI) que respalda el

EVA 
Contenidos del

DI

Estrategias

instruccionales

Metodología

Recursos

Evaluación

Gestión del

Conocimiento manera didáctica con la que aborda el EVA los contenidos presentados
Motivación a

aprender

Procesos

cognitivos

básicos

Procesos

cognitivos

superiores

Características

de la audiencia

Diversidad en

las actividades

Organizadores

previos

Técnicas para el abordaje de problemas

Teoría del

Aprendizaje

Metacognición

Dicotó

mico

Fuente: Elaboración Propia

\subsection{Tabla de ítemes del instrumento para el análisis de contenido}

De acuerdo a las características que debe tener una lista de chequeo o de cotejo, tipo de instrumento elegido para este estudio y justificado previamente en el Capítulo 3, la redacción de ítemes supuso la construcción de oraciones que, obedeciendo a una categoría específica, permitieran responder la ausencia o presencia de dicha categoría. 
En este sentido, los ítemes construidos para el Instrumento (ver Tabla 10) fueron:

Tabla 4.

Tabla de Ítemes.

Categoría

Dirección en la web

Velocidad de carga

Contenido

autoexplicativo

Mapa de

navegación

Menú de ayuda

Ejecución de

programas y

herramientas

Bidireccionalidad

Canales de

comunicación

Actividades

interactivas

Incrustaciones de

herramientas de

autor

Herramientas

multimediales

Hipervínculos
Número

del Ítem

Ítem

1 La dirección web del entorno de aprendizaje es de fácil recuerdo

2 La velocidad de carga de la página Web inferior a los 5 segundos

3 Al entrar al entorno de aprendizaje su manejo se explica por si solo

4 El entorno de aprendizaje posee mapa de navegación en un menú específico

$5 \quad$ El entorno de aprendizaje contiene un menú de ayuda

6 Los programas y herramientas que se ejecutan desde el entorno de aprendizaje funcionan correctamente

$7 \quad$ El entorno de aprendizaje permite el intercambio de información con sus usuarios

8 Existe la posibilidad de enviar correos electrónicos desde el entorno de aprendizaje

9 Existe la posibilidad de establecer chats desde el entorno de aprendizaje

10 Hay comunicación mediante enlaces con al menos una red social (FaceBook, Twitter, Linkedin, Hi5, YouTube...)

11 El entorno de aprendizaje propicia la actividad interactiva a través de herramientas de la Web 2.0.

12 En las actividades interactivas se hace uso del refuerzo y de ayudas para aproximar al usuario al procedimiento correcto

13 El entorno virtual de aprendizaje hace uso de herramientas de autor en el desarrollo de sus actividades

14 El entorno virtual utiliza programas multimediales que le pueden ser atractivos al usuario

15 Se hace uso de audiovisuales para promover la asociación de contenidos conceptuales

16 El entorno de aprendizaje hace uso de hipervínculos "links" que redireccionan al usuario a otras páginas Web para que incremente su información respecto a una 
Información

actualizada

Diseño de pantallas

Calidad técnica y estética en sus

elementos

Medidas de los

cuadros

Entorno interesante

Disposición de las imágenes

Espacios

publicitarios

Imagen del autor

del entorno

Tipografía temática planteada

17 La información que se presenta en el espacio es de una fuente veraz

18 La información que se presenta en el espacio tiene una antigüedad menor a 2 años

19 Los colores predominantes en el entorno son de alta intensidad

20 Los objetos utilizados en el entorno son armónicos en su estética

21 El entorno muestra calidad técnica en su elaboración

22 El entorno muestra que fue realizado a través de una plantilla prediseñada

23 Hay un adecuado uso de las medidas tanto en las entradas como en las incrustaciones demostrando que ninguna de éstas excede de los márgenes del entorno

24 Las pantallas del entorno despiertan el interés a revisar su contenido

25 Las imágenes están predominantemente en el lado izquierdo del entorno virtual

26 Las imágenes están predominantemente en el lado derecho del entorno virtual

27 Las imágenes están colocadas aleatoriamente en el entorno virtual

28 Hay espacios publicitarios (AdSense) que pueden producir un lucro para el autor del entorno virtual

29 Existe en el entorno una imagen fotográfica del autor

El tamaño de tipografía utilizada en el entorno es de fácil lectura

31 El tipo de tipografía utilizada en el entorno es provenientes de las fuentes tradicionales de herramientas ofimáticas de Windows, Mac y Linux.

32 En los textos se hace uso de discriminadores en las palabras (resaltados con colores fluorescentes, uso de negrillas, variaciones de tamaño, cursivas y subrayados que no son hipervínculos)

Descripción del

Autor del entorno

Ortografía

Signos de

puntuación
El entorno contiene una biografía del autor y se señalan sus logros académicos.

4 El entorno carece de errores ortográficos en su construcción

5 El entorno hace uso adecuado de los signos de puntuación en su construcción 
Legibilidad del

texto escrito

Coherencia

Cohesión

Códigos

comunicativos

Confianza en el

discurso escrito

Categoría del

discurso escrito

Planos del discurso

escrito

Objetivos,

propósito

Contenidos del DI

Estrategias

instruccionales,

Metodología y

Recursos

Evaluación

Gestión del

Conocimiento

Motivación a

aprender

Procesos cognitivos

básicos

Procesos cognitivos

superiores

Características de la audiencia
36 Los textos escritos son de fácil comprensión por parte del usuario y hace uso de un lenguaje sencillo y claro en los textos

37 Existe una secuencia lógica en los textos escritos en el entorno virtual

38 Hay una unión lógica de ideas en los textos escritos en el entorno virtual

39 En los textos escritos hay un uso correcto entre significados y significantes

40 En las actividades propuestas dentro del entorno se hace uso frecuente de preguntas que contienen el “¿qué?" y "¿cuáles?"

41 En las instrucciones y enunciados de las actividades se hace uso de "tuteos"

42 Las explicaciones realizadas en el entorno de aprendizaje requieren de conocimientos previos de alto contenido especializado.

43 El discurso utilizado en el entorno virtual promueve la interacción entre los usuarios

44 El discurso utilizado en el entorno virtual promueve la interacción entre el usuario y el texto escrito

Se especifican los objetivos, el propósito de uso y al menos los contenidos conceptuales del entorno educativo Web

Se plantean posibles estrategias didácticas, la metodología instruccional y los recursos instruccionales a ser aplicadas con el uso del ambiente de aprendizaje

47 Se especifican las evaluaciones posibles en el entorno educativo web, bien sea de entrada, formativa y/o sumativa.

48 Dentro del entorno educativo se promueve el intercambio de ideas a través de foros de discusión En el entorno educativo virtual se motiva a aprender a través de demostraciones, actividades llamativas, ideas novedosas y/o indicaciones para el estudio eficaz de contenidos

Se estimula la percepción, la atención, la memoria, la 50 inteligencia, el pensamiento y el uso adecuado del lenguaje a través de las actividades propuestas en el entorno virtual de aprendizaje

51 Se estimula la creatividad a través de las actividades propuestas en el entorno virtual de aprendizaje

52 El ambiente de aprendizaje toma en cuenta la edad de la audiencia y dispone de actividades acordes al nivel de 
Diversidad en las

actividades

Organizadores

previos

Técnicas para el

abordaje de

problemas

Teoría del

Aprendizaje esarrollo de la audiencia

El entorno propone diversos tipos de actividades e itinerarios que permiten diversas formas de utilización y acercamiento al conocimiento.

54 Para la presentación de un tema determinado el autor del entorno inicia con el uso de organizadores previos.

55 Se hace uso frecuente de la técnica de la pregunta

Se hace uso de la técnica del Aprendizaje Basado en Problemas (ABP)

57 Se utilizan mapas conceptuales en la presentación temática del ambiente

58 Se produce la asignación de actividades tipo cuestionario, guía de preguntas y encuestas

59 Hay estimulación del desarrollo de la inteligencia lingüística, lógica-matemática, espacial, musical, intrapersonal, interpersonal y naturalista.

60 Las actividades estás separadas por edades cronológicas.

61 Se facilita el aprendizaje a partir de ensayo y error.

62 Se tutorizan las acciones de los usuarios de manera síncrona o asíncrona

Metacognición

63

Fuente: Elaboración Propia Hay estimulación para el desarrollo de habilidades metacognitivas.

\section{CONCLUSIONES}

Una vez manejada la información obtenida a través de la observación directa y documental, se presentan las siguientes conclusiones basadas en el diseño de un instrumento para el análisis de contenido de un Entorno de Aprendizaje Colaborativo.

En cuanto a las principales categorías que conforman un EAC, luego de haber realizado la observación directa de un trío de entornos se obtuvieron por saturación en agrupación en dimensiones tecnológica, discursiva y didáctica, las siguientes categorías: Dirección en la Web, velocidad de carga, contenido autoexplicativo, ejecución de programas y herramientas, bireccionalidad, canales de comunicación, herramientas multimedia, actividades interactivas, incrustaciones de herramientas, hipervínculos, información actualizada, diseño de pantallas, calidad técnica y estética en los elementos del ambiente, medida de los cuadros, entorno interesante, disposición de las imágenes, identificación de (los) autor(es), tipografía, ortografía, signos de puntuación, legibilidad del texto, coherencia, cohesión, códigos comunicativos, confianza, categoría y planos del discurso escrito, componentes del diseño instruccional, gestión del conocimiento, motivación al aprendizaje, procesos 
cognitivos, características de la audiencia, diversidad de actividades, organizadores previos, Teorías del Aprendizaje y aspectos metacognitivos.

Cuando se realizó la revisión a cerca de las categorías propuestas como aspectos conformantes de un EAC a partir del trío de teóricos: Hassan y Martin (2003), UWEC (2003) y Pere Marquès (2002), se pudo encontrar con el mismo criterio de saturación que hay cierta dispersión de criterios, obteniéndose como comunes las categorías de: Velocidad de carga, ejecución de programas y herramientas, bidireccionalidad, hipervínculos, información actualizada, diseño de pantallas, calidad técnica y estética en los elementos del ambiente, entorno interesante y descripción del autor del entorno.

Una vez elaborados sendos subsistemas de categorización se obtuvo por contraste el sistema de categorización integrado. Este sistema estuvo conformado tanto por la observación teórica como por la observación directa, lo que le otorga vigencia a las categorías recomendadas. Aplicando entonces el criterio de selección, tanto por agrupación mayoritaria de la categoría como por saturación en el grupo de fuentes de información, se extrajeron las categorías que conformaron el instrumento objeto de estudio en términos de aspectos tecnológicos, discursivos y didácticos, las cuales fueron:

a) Aspectos tecnológicos: dirección en la Web, velocidad de carga de la página, autoexplicación de contenido, mapa de navegación, menú de ayuda, ejecución de programas y herramientas, Bidireccionalidad, canales de comunicación, actividades interactivas, incrustaciones de herramientas de autor, herramientas multimediales, hipervínculos e información actualizada.

b) Aspectos discursivos: Diseño de pantallas, calidad técnica y estética en sus elementos, medidas de los cuadros, entorno interesante, disposición de las imágenes, espacios publicitarios, imagen del autor del entorno, tipografía, descripción del Autor del entorno, ortografía, signos de puntuación, legibilidad del texto escrito, coherencia, cohesión, códigos comunicativos, confianza en el discurso escrito, categoría del discurso escritoy, planos del discurso escrito.

c) Aspectos didácticos: objetivos y propósito del DI, contenidos del DI, estrategias instruccionales, metodología, recursos, evaluación, gestión del conocimiento, motivación a aprender, procesos cognitivos básicos, procesos cognitivos superiores, características de la audiencia, diversidad en las actividades, organizadores previos, técnicas para el abordaje de problemas, teoría del aprendizaje, metacognición.

El instrumento diseñado está basado en una Lista de Cotejo en formato tradicional y digital, con 63 ítemes que cubren las categorías que emergieron de las observaciones, las cuales proporcionan un análisis de contenido a partir de la construcción de párrafos desde una lista de verbatum predefinida según la elección hecha en el instrumento, de oraciones claras y concisas que surgieron de aportes teóricos específicos, agrupado en tres párrafos, uno por cada aspecto observado (tecnológico, discursivo y didáctico). 
Como hallazgo adicional, es posible inferir que los teóricos no le otorgan un nivel de importancia superior a los aspectos derivados de la aplicación de las Teorías del Aprendizaje lo que deja un poco desierto los aspectos didácticos de los EAC, siendo esto contradictorio respecto al fin con el que éstos se construyen. No así con lo concerniente a las aplicaciones tecnológicas y aquellas características discursivas iconográficas que subyacen de una mejora en la tecnología aplicada. Es posible que por razones cronológicas (las investigaciones teóricas aquí trabajadas datan 2002 y 2003) y por la rapidez de los avances en cuanto a aplicaciones tecnológicas digitales, se le de relevancia a aquello "nuevo" y se dé por entendido aspectos tradicionales vinculantes al hecho educativo como lo es lo que concierne a la didáctica.

Es desde esta visión que se origina un problema aquí planteado: el instructor no experto en didáctica y/o discurso pero si en el contenido de su especialidad y en competencias tecnológicas, diseña, construye y pone en línea un EAC que dista del propósito esencial para lo cual fue ideado. Un profesional de un ámbito no educativo que incursiona en la instrucción.

\section{REFERENCIAS}

\section{Libros completos:}

Ausubel, D. y Novak, N. (1983), Psicología Educativa: Un Punto de Vista Cognoscitivo. 2o Edición, Ed. Trillas. México.

Arias, F. (2006), El Proyecto de Investigacion, , $5^{\circ}$ edición, Caracas:Episteme

Bardin, L. (1996) Análisis de contenido. $2^{\circ}$ ed. Akal.

Bandura, A. (1987). Pensamiento y acción: Fundamentos sociales. Barcelona, España

Bolívar, A.; (2005) Discurso e Interacción en el texto escrito. Consejo de desarrollo científico y humanístico. Segunda edición, Universidad Central de Venezuela. Caracas.

Bruner, J. (1966) Toward a Theory of Instruction. Cambridge, Harvard University Press, Estados Unidos de Norteamérica.

Aguilar, J. (2008) El diseño de la instrucción en la planificación de la enseñanza. Manuscrito inédito, Universidad Metropolitana, Caracas, Venezuela.

Certad, P. (2011) Enseñando Química a través del Edublog como Ambiente de Aprendizaje. ISBN: 978-3-8443-4223-9. Saarbrücken:EAE

Certad, P. y Rincón, L. (2011) La Brecha Digital en el Contexto Educativo Venezolano: Estudio de Caso. ISBN 978-3-8454-9962-8. Saarbrücken:EAE

Fernández, M. y Martínez, M. (2009) Nuevos ambientes de enseñanza: miradas iberoamericanas sobre Tecnología Educativa. Caracas: El Nacional.

Ferraté, G. (1997) Internet como entorno para la enseñanza a distancia. En: Tiffin, J.; Ragasingham, L.. En busca de la clase virtual: La educación en la sociedad de la información. Barcelona:Paidós.

Hassan, Y., Martín F., Hassan D., y Martín, Ó., (2006) Arquitectura de la Información en Entornos Virtuales los de Aprendizaje. Aplicación de la Técnica de tarjeta de clasificación y Análisis cuantitativo de los Resultados. Revista El Profesional de la Información, Volumen 13, Número 2 (01 de marzo 2004), pp. 93 - 99. ISSN: 1386-6710

Hostil, O. (1969) Content analysis for the social sciences and humanities. Addison:Wesley. 
Hurtado de Barrera, J. (2000) Metodología de la Investigación Holística. Caracas:Sypal. Gardner, H. (1998) Inteligencias Múltiples: una teoría en la práctica. Barcelona:Paidos Kaye, A. (1993) Technologies for Educational Interaction and Colaboration Institute of Educational Technology, United Kingdom:Open University

Salinas, J. (2004) Cambios metodológicos con las TIC: estrategias didácticas y entornos virtuales de enseñanza- aprendizaje. En Bordón: Revista de orientación pedagógica, ISSN 0210-5934, Vol. 56, No 3-4.

Sambrano, J. y Steiner, A. (2004) Los mapas mentales: Agenda para el éxito. Alfadil Ediciones.

Skinner, B.F. (1975) Sobre el conductismo. Fontanella: Barcelona.

Thiebaut, C. (1998) Conceptos fundamentales de la Filosofía, Madrid:Alianza Editorial.

Vygotsky, L. (1931), El Desarrollo de los Procesos Psicológicos Superiores. Barcelona:Crítica.

Wilson, J. (1995): Cómo valorar la calidad de la enseñanza. Madrid:Paidos.

\section{Artículos en papel y electrónicos:}

Adúriz-Bravo, A. (2010). Hacia una didáctica de las ciencias experimentales basada en modelos. A 'CiDd: II Congrés Internacional de Didàctiques 2010. Girona:Universitat. Consultado el 12 julio 2010 y disponible en: http:/ / hdl.handle.net/10256/2774

Abela, J. (2003). Las técnicas de Análisis de Contenido: una revisión actualizada. [en línea] Disponible en: http:/ / www.fundacion-centra.org/pdfs/S200103.PDF

consultado: 21 de septiembre de 2011.

Anderson, J. (1973) Verbatim and propositional representation of sentences in immediate and long-term memory. [en línea] Universidad de Yale, EEUU. Disponible en

http://www.sciencedirect.com/science/article/pii/S0022537174800393 revisado el 12 de diciembre de 2011

Casillas, L; Gibert, M; y Pérez, O. (s/f) Bases de datos en MySQL. [en linea] disponiblehttp:/ / ocw.uoc.edu/computer-science-technology-and-

multimedia/bases-de-datos/bases-de-datos/P06_M2109_02151.pdf revisado el 22 de enero de 2012. Universidad Oberta de Cataluña, Barcelona.

Castañeda, L., y Sánchez, Ma del Mar. (2009) Entornos e-learning para la enseñanza superior: entre lo institucional y lo personalizado. Pixel-Bit. Revista en línea de Medios y Educación, (Julio-Sin mes) : consultado el 5 de octubre de 2011 y disponible en:

http:/ / redalyc.uaemex.mx/src/inicio/ArtPdfRed.jsp?iCve=36812381014>

Gros, B. y Silva, J. Barberà, E. (2006). Metodologías para el análisis de espacios virtuales colaborativos. RED. Revista de Educación a Distancia, número 16. Consultado el 01 de septiembre de 2011 en http:/ / www.um.es/ead/red/16

Hassan, Y., y Martín, F (2003) Guía de Evaluación Heurística de Sitios Web. [en línea] Revista Electrónica No Solo Usabilidad. ISSN 1886-8592 disponible en http:/ / www.nosolousabilidad.com/articulos/heuristica.htm y revisado el 12 de noviembre de 2011.

Marquès, P. (2002). Evaluación de los portales educativos en Internet. Revista Pixel.Bit, [18] 
Marzal, M. A; Cuevas, A. Colmenero, M. J. (2005) Instrumentos de utilidad en análisis de contenido para la organización de documentos digitales educativos. En: CONGRESO ISKO ESPAÑA. Barcelona:Anales [s.n.]

Panitz, T. (2004) Si, hay una gran diferencia entre el Paradigma del Aprendizaje Cooperativo y el del Aprendizaje Colaborativo. Revista Iberoamericana de Educación. ISSN: 16815653

Piaget, J. (1952) Discours du directeur du Bureau international d'éducation". En: Quinzième Conférence internationale de l'instruction publique: procès- verbaux et recommandations. Ginebra, Oficina Internacional de Educación.

Piñuel, J. (2002) Epistemología, metodología y técnicas del análisis de contenido. Facultad de Ciencias de la Información Universidad Complutense de Madrid. Estudios de Sociolíngüistica 3(1) pp. 1-42.

Porta, L. y Silva, M. (2003) La investigación cualitativa: El análisis de contenido en la investigación educativa, en Revista Investigación para una mejor educación. Mar del Plata:Grade [s/n]

Ramirez, T. (2007). Cómo hacer un trabajo de Investigación. Caracas:Panapo

Rodríguez, G., Gil, J., Garcés, E. (1999) Metodología de Investigación Cualitativa. Editorial Algibe.

Rufo, P. (2006) HTML. [en linea] en http://www.asptutor.com/zip/cbhtml.pdf revisado el 22 de enero de 2012

Tondeur, J., van Braak, J. y Valcke, M. (2007). Towards a typology of computer use in primary education. Journal of Computer Assisted Learning, 23, pp. 197-206.

Universidad Pedagógica Experimental Libertador (2006), Manual para la elaboración de Tesis Doctorales, Trabajos de Grado y Trabajos Especiales. Caracas.

University Of Wisconsin - Eau Claire (2003) Ten C's For Evaluating Internet Sources. [en línea] disponible en:

http://www.montgomerycollege.edu/Departments/writegt/htmlhandouts/Te n\%20C\%20internet\%20sources.htm y revisado el 11 de noviembre de 2011.

Van Der Hens, C. (2003) ¿Qué es el PHP?. [en linea] disponible en http://www.maestrosdelweb.com/editorial/phpintro/ y revisado el 22 de enero de 2012.

\section{Informes técnicos y tesis:}

Del Valle, M. (2010); El análisis del discurso pedagógico en la enseñanza de la Historia, Tesis Doctoral, Instituto Pedagógico de Caracas, Doctorado en Educación. 